\title{
Effect of COVID-19 on US TV Stocks Based on Fama- French Model Analysis
}

\author{
Long Long ${ }^{1, \mathrm{a}, \dagger}$, Weichao $\mathrm{Wu}^{2, \mathrm{~b}, \dagger}$, Yuxiang Weng ${ }^{3, \mathrm{c}, \dagger}$, and Chaobang Zhang ${ }^{4, \mathrm{~d}, \dagger}$ \\ ${ }^{1} I B S S, X i^{\prime}$ an Jiaotong Liverpool University, China \\ ${ }^{2}$ University of Toronto St. George Campus, Canada \\ ${ }^{3}$ Affiliated high school of Guangzhou University, China \\ ${ }^{4} X i$ 'an GaoXin no.1 high school, China \\ along.long19@student.xjtlu.edu.cn, ${ }^{b}$ weichao.wu@mail.utoronto.ca, ${ }^{c} 1724836792 @ q q . c o m,{ }^{d} 2825470299 @ q q . c o m$. \\ These authors contributed equally.
}

\begin{abstract}
The COVID-19 has become a global crisis since it broke out at the beginning of 2020, which has led to a global economic recession and a deep influence on the stock market. This research adopted the Fama-French model to analyze the impact of the epidemic on the listed TV companies' stock in the US stock market. The research data was consulted from the CRSP database with the factors of the Fama-French model and the value \& equal-weighted returns for 38 industry portfolios in the US market. The research selected the data above from April 1, 2019, to January 29, 2021 and chose March 1 as the date of the outbreak of the epidemic in the US, which represented the timeline before and after COVID19. After multiple linear regression, it was found that COVID-19 has had a significant effect on the TV industry. The analysis of five factors concluded that the market preference shows the following characteristics: value stock, high profitability, and aggressive investment style. It is recommended that the investors who want to invest in the TV industry in the US stock market can take the stocks with the above features as the investment targets in the post-epidemic period, and this theory can also be applied to future investment whenever an analogous event happens.
\end{abstract}

Keywords: COVID-19, US TV stocks, Fama-French model analysis.

\section{INTRODUCTION}

Harry Markowitz developed the model of portfolio theory which is the cornerstone for CAPM [1]. He also showed that a portfolio should contain except return and risk. According to him, the model of portfolio selection, William Sharpe and John Lintner invented the Capital Asset Pricing Model CAPM, which has been challenged by many economists in the past [2,3]. The black version of the CAPM, which can adapt to a tradeoff of average return for the market beta, has some success in the early empirical test [4]. In the latter, however, research begins to discover variables like various price ratios, a size that adds to the interpretation of average returns paid by beta. CAPM, a large amount of recent empirical tests, states that there are many obvious disadvantages of explaining the model, arguing the stock returns are more reasonably related to the total variability and book value of the stock rather than a beta calculated. The problems are serious enough to invalidate most applications of the CAPM, using the CAPM either risk investment decision or for portfolio decisions and imagining an adviser who has proposed adding a stock to a portfolio with a $\$ 100$ share price. The adviser uses the CAPM to justify the price with a discount rate of $13 \%$. The adviser's investment manager can take this information and compare it to the company's past performance and its peers to see if a $13 \%$ return is a reasonable expectation. Assume in this example that the peer group's performance over the last few years was a little better than $10 \%$, while this stock had consistently underperformed with $9 \%$ returns. The investment manager should not take the adviser's recommendation without some justification for the increased expected return.

The impact of COVID-19 could be examined through various industries containing global shifts in flux on the stock market. The recession resulted in rising unemployment and limited commercial flight, and the rise of pharmaceutical companies in contrast to the hospitality industry hit hard. For all of this, central banks in many countries, including the UK, have slashed 
interest rates. That should, in theory, make borrowing cheaper and encourage spending to boost the economy. Some markets recovered ground in January this year, but this is a normal tendency known as the "January effect". Analysts are worried that the possibility of further lockdowns and delays in vaccination programs might trigger more market volatility this year.

Qi discovered a new application of the FF 5 factors model. He states that the FF 5-factors model is usually used in the North American markets, while there are extremely limited cases in the Chinese stock market [5]. It stresses in the conclusion that the outstanding performance of the 5-factors model compared with the 3factors model using Shanghai Stock Exchange data. Furthermore, the most attractive result from His is that the significance of different factors varies dramatically in Chinese and the U.S. markets. He mentions that this results from the construction of the portfolio model that he applied in the research. Similarly, Nicholas et al. use the Fama-French model to investigate the price setting of the African market asset and capital, called African Stock Markets (ASMs). They focus on the possible methods of market segments, which divide the market into a regional stage or a national level. Remarkably, they take a large range of data from ASMs into consideration, which concludes that the flow of the returns might be sensitively and negatively affected by the method of dividing the market (Nicholas et al.) [6]. In contrast, Keiichi and Hitoshi argue that the FF Five-Factor Model might not be qualified enough in the background of the Japanese market. They claim that the RMW and CMA indices are not statistically significant. Specifically, the significant level of different factors is not identical: while HML owns $1 \%$ significant level, the CMA is only at the $10 \%$ significant level, which means in different markets, the estimation of the FF Five-Factor Model is not always satisfying (Keiichi \& Hitoshi). They conclude that the FF Five-Factor Model is likely to be overfitted to the Japanese market compared to the Three-Factor Model [7]. However, we could still see the estimation potential of the FF Five-Factor Model. Therefore, it is reasonable to claim that the FF Five-Factor Model is suitable for most of the cases, while at the same time, tests of the fitness of all five factors should be conducted to avoid over-fitness.

Considering the global pandemic background, it is obvious that the COVID-19 brings an overwhelming turbo to the global economy. Boshkoska and Jankulovski published their research report, which focuses on the coronavirus's impact on the global economy [8]. The research uses the data analysis method in the process of research. By enumerate and analyze authoritative data, such as IMF global economic growth rate, S \&P global ratings, and OECD estimate, the study identifies that the consequences of the outbreak of the COVID-19 are being felt in all segments and the global economic growth suffers a heavy blow. In addition, based on the industries index, the study emphasizes that the manufacturing and service industries are particularly affected by serious losses. The government should map and implement actions to reinvigorate the economy. Spanulescu and Gheorghiu adopt the Econophysics approach and model to analyze the impact of COVID-19 on the world economy [9]. The research proposes and analyzes the generalized Econo-physics model with a combination of three other Econo-physics models that reflect economic development, which are the economic amplifier model, the Econo-physics model of the Cobb-Douglas production function, and the econophysics model of the mixed economy. The research shows that apart from COVID-19 leads to reduced production activities, unemployment, food crises, and deterioration of the world economy, the defective measures of the governments also exacerbate the impact on the global economy. Matos, Costa, et al. use partial coherencies, gains, and phase-difference diagrams to analyze the relationships between the confirmed cases and deaths caused by COVID-19 worldwide and the S \&P 500 return in the time-frequency domain [10]. In addition, the study implements a parametric test for Granger-causality in quantiles. In the research report, the major finding is that the cycles of deaths in the US could be anticipated by low-frequency cycles of the US market index in the first half of April 2020 in an anti-phasic way. Meanwhile, the research also shows that the energy and telecom sectors are closely related to the epidemic situation.

Our research focuses on the American stock market during the pandemic period. To understand how the stock market of different fields has been changed during this year, we aim to change various American industries that might be affected by the turbulence. Our target is fieldspecific, which targets the TV and broadcasting industries in America. The heart of our objective is to discover the reaction of the TV and broadcasting industries between the pre-pandemic period and the postpandemic period. The significance of using TV and broadcasting industries stresses that this industry is one of the most likely industries that differ dramatically from the situation before the COVID-19 threats. With the following modelling using the FF 5-factor model, we will specifically discover the movement of 5 different factors in our selected model.

\section{METHOD}

In 1992, Fama and French studied the factors determining the difference of stock returns in the American stock market. They found that the beta value of the stock market could not explain the difference of stock returns. In contrast, the market value, book-tomarket ratio, and price-earnings ratio of listed companies could explain the difference of stock returns. Fama and French th that the above excess return is the compensation for the risk factors not reflected by the $\beta$ in CAPM. Accordingly, Fama and French pointed out in 
1993 that a three-factor model could be established to explain the stock return rate [11]. According to the model, the excess return of a portfolio can be explained by its exposure to three factors: the market asset portfolio $\left(\mathrm{R}_{\mathrm{M}}\right.$ - $\mathrm{R}_{\mathrm{F}}$ ), the market value factor (SMB), and the book to market ratio factor (HML). This multi-factor equilibrium pricing model can be expressed as:

$$
R_{i}=a_{i}+b_{i} R_{M}+s_{i} E(S M B)+h_{i} E(H M I)+e_{i}
$$

If the three factors in the three-factor model can fully explain the excess return caused by various risks, then the true value of any stock and any portfolio $a_{i}$ should be 0 . In the past 20 years, many scholars have conducted empirical analysis on the three-factor model and found that the $\mathrm{a}_{\mathrm{i}}$ of some stocks is significantly non-zero, which indicates that the three risks (factors) in the three-factor model cannot explain all excess returns. Later, Fama and French found that there is also the risk of profit level and risk of investment level in addition to the above risks, which can also bring the excess return of individual stocks and put forward a five-factor model in 2013. This model more fully explains the excess return of individual stocks, and its expression is as follows:

$$
\begin{aligned}
& R_{i}=a_{i}+b_{i} R_{M}+s_{i} E(S M B)+h_{i} E(H M I)+r_{i} E(R M W)+ \\
& c_{i} E(C M A)+e_{i}
\end{aligned}
$$

To be more specific, the definition of each factor is as follows, Rm: Market risk refers to the uncertainty caused by changes in market trends. To put it simply, it is the risk that market fluctuations lead to individual stocks also fluctuating. For example, the stock price of a company that has done well has fallen along with the broader market, or the stock price of a company that has not done so well has risen along with a bull market. SMB: Market value risk refers to the fact that the size of a company has a direct impact on the risk of the company's stock: a small size of assets will increase the risk relative to the other side, and large size of assets will reduce the risk relative to the other side. HMI: The book-to-market ratio is the owner's equity divided by the market value. The book-to-market ratio describes the additional financial distress risk of the company, indicating that the company's market value is lower than the company's valuation. These companies are generally not very good in sales or profitability, so they need higher revenue to compensate for the low B/M companies. RMW: Profitability level risk refers to the higher profitability of the industry is generally accompanied by higher risk. CMA: The reinvestment rate can measure the level of investment. We believe that companies with a low investment rate are riskier, and investors demand higher returns for these companies and vice versa.

\section{RESULT}

The research data was consulted from the CRSP database (Center for Research of Security PRICES), which consists of the factors of the Fama-French model and the value \&equal-weighted returns for 38 industry portfolios in the US market. The research selected the data mentioned above from April 1, 2019, to January 29, 2021, and chose March 1 as the date of the outbreak of the epidemic in the US, which represented the timeline before and after COVID-19. The research then determined the TV industry in the US as the object and implemented the Multiple Linear Regression method to analyze the change in data caused by COVID-19 (Table 1).

Table 1 Outcome of Multiple Linear Regression (Before COVID-19)

\begin{tabular}{lllll}
\hline & Coefficients & $\begin{array}{l}\text { Standard } \\
\text { deviation }\end{array}$ & t Stat & P-value \\
\hline $\begin{array}{l}\text { Mkt- } \\
\text { RF }\end{array}$ & 0.836 & 0.052 & 15.965 & $7.15 \mathrm{E}-39$ \\
SMB & -0.090 & 0.095 & -0.950 & 0.343 \\
HML & 0.120 & 0.095 & 1.260 & 0.209 \\
RMW & 0.037 & 0.152 & 0.243 & 0.808 \\
CMA & -0.346 & 0.185 & -1.873 & 0.062 \\
\hline
\end{tabular}

Table 2. The outcome of Multiple Linear Regression (After COVID-19)

\begin{tabular}{lllll}
\hline & Coefficients & $\begin{array}{l}\text { Standard } \\
\text { deviation }\end{array}$ & t Stat & P-value \\
\hline $\begin{array}{l}\text { Mkt- } \\
\text { RF }\end{array}$ & 0.864 & 0.030 & 28.372 & $1.97 \mathrm{E}-76$ \\
SMB & 0.050 & 0.074 & 0.670 & 0.504 \\
HML & 0.256 & 0.061 & 4.214 & $3.62 \mathrm{E}-05$ \\
RMW & 0.380 & 0.124 & 3.066 & 0.002 \\
CMA & -0.562 & 0.144 & -3.911 & 0.000 \\
\hline
\end{tabular}

As shown in Table 1, there is no evident change in the significance of the Mkt-RF factor and SMB factor. However, the coefficients of the HML factor, RMW factor, and CMA factor had an obvious change from insignificant to significant.

\section{DISCUSSION}

\subsection{SMB and Mkt-RF}

Based on the data provided above derived from the multi linearization method of the TV industry, we found that the significance of Mkt and SMB didn't change at a $5 \%$ significant level, and the coefficients were also not influenced for Mkt. Because SMB's significance is nearly zero based on $\mathrm{t}$ Stat, we should ignore its coefficient, meaning SMB plays no role in the Fama- 
French model. There is no difference between the profitability between large and small corporates. For example, canceled live events like sports helped advertisers reach specific audiences such as young men who don't otherwise watch much live TV. Given that the NBA viewers tend to be younger than cable TV viewers increased viewing time in an area like news won't fully negate the losses in sports watching. It's also possible that if unemployment rises substantially, consumers will be thriftier and choose to cancel TV or streaming subscriptions to save money. There will be even more eyes than usual on how many subscribers pay for TV and streaming services during the next quarter. All those factors contribute to the null value of SMB: TV industries are being affected totally.

Since Mkt's value is less than 1 before and after the pandemic, Mkt is not sensitive and has a weak period, not been affected by Covid-19 too much. For example, the global television network market data is expected to grow from $\$ 107.8$ billion in 2019 to $\$ 134.8$ billion in 2020 as the TV viewership has been increasing globally [12]. During the outbreak, people are confined to their homes due to the spread of COVID-19 and, therefore, spending more time on their television sets and consuming more content than usual. The market is expected to stabilize and reach $\$ 133.7$ billion at a CAGR of 5.5\% through 2023[12]. North America was the largest region in the television network services market in 2019. This trend is beneficial, but it's at the stages of increasing returns of scales, simply meaning stably increasing without significant growth in sales.

\section{2. $H M L$}

In contrast, the HML factor turned out to be significant based on the result. Obviously, during the preCOVID section, the HML has a T-stat absolute value that was lower than 1.96 , and at the same time, its p-value shows no signs of HML in the market in the 0.05 significant level. However, the HML factor in the market statistically flipped over, which means that it became significant during the post-COVID section, which became significant based on the new t-stat and p-value. Furthermore, its coefficient was positive during the postCOVID section, which is remarkable and statistically significant that TV or broadcasting companies with high book-to-market value outperformed those with low book-to-market value. Identically, that also exhibited that in the TV industries, the existence of the COVID pandemic considerably and positively accelerates the value of value stocks against the growth stocks. Furthermore, cooperated with the SMB factor interpretation, which has a positive coefficient but not significant enough, smaller companies will outperform the larger companies since our SMB factor is not significant.
Specifically, in the TV industries, we saw constantly indifferent or insignificant factor SMB, which is not in the list of effective factors based on the result. This creates a better explanation for the HML factor in the U.S. TV and broadcasting market: With the background of the global pandemic, the smaller broadcasting companies might not be able to outperform the larger companies such as Netflix and Spotify. Based on the historical prices of Netflix and Spotify, it is obvious that there is a considerable increase in their stock prices started from March 2020, which were also at the time when the pandemic trend was officially recognized and acknowledged by the world $[13,14]$. In contrast, the TV and broadcasting industries in the U.S. show a pessimistic, unstable, and turbulent path of the $\mathrm{P} / \mathrm{E}$ ratio on average during 2020 [15]. This is reasonable to connect the destructive economic effect generated by the pandemics and the recessive market of the whole industry during this period. In terms of larger TV companies such as Netflix and Spotify, however, they were comparably stabler than those smaller companies. Therefore they were overwhelming in allocating the whole TV market, during which they were considered a value stock. As mentioned before, the HML displayed the relatively healthy and positive status and the overwhelming competitive capability during this special period.

\section{3. $R M W$}

According to the data above, we can see that the RMW factor was not before the pandemic (0.243). However, it changed to be significant after the pandemic (3.066). Besides, the coefficient is positive, which means the market prefers to robust company compare to before. Before the pandemic, the whole TV industry was stable, and people did not prefer the specific type of company. As mentioned above, the overall growth rate of the TV industry was not well and continued to decline. This can explain why the RMW was not significant before the pandemic. However, because of the pandemic, people could not do outdoor activities or entertainment. Still, it was actually a great opportunity for the TV industry because people had more time to stay at home, and they started to watch more TV. Therefore, the robust company is growing at a rapid speed. For example, Netflix, according to the annual report and stock information published by Netflix [16, 17], after the outbreak of the pandemic, the number of paying subscribers has soared by $30 \%$ and now exceeds 200 million. Netflix had 37 million new subscribers last year, including 8.5 million in the fourth quarter alone. For all of 2020, Netflix generated nearly $\$ 25$ billion in revenue and nearly $\$ 2.8$ billion in profit, up $47.9 \%$ from the previous year. The company's shares had been pushed up more than 9 percent. The most impressive thing was that Netflix got a return of 3,767 percent, which implies a 44.1 percent 
CAGR. All this data shows that people preferred to invest in the robust company after the pandemic.

\section{4. $C M A$}

Based on the result, the CMA factor had been insignificant before COVID-19. It became significant after the epidemic outbreak, and the coefficient presented was negative, which reflected a market preference for the companies with aggressive investment style. According to MarketLine Industry Profile: Broadcasting \& Cable TV in North America, the total revenues of the North American broadcasting \& cable TV market were $\$ 181.8$ bn in 2019 , representing a compound annual rate of change (CARC) of $-1.4 \%$ between 2015 and 2019, and it is anticipated that the market value would continue to decline in the future, which indicated the market sluggishness[18]. Moreover, the COVID-19 hit the market and caused a decline in listed TV companies. Broadcasting \& Cable TV in North America states that traditional media companies are under threat from tech and streaming video companies, such as Amazon and Netflix, and acquisition is an effective way to deal with this threat [18]. The shrinkage of market value in the period of post-epidemic provided the opportunity for companies with sufficient capital to make mergers and acquisitions. By doing so, the companies could maintain a competitive advantage, expand market share and gain scale effect. Above all, the companies with aggressive investment styles were preferred because of a better market performance after the low-price acquisitions.

\section{CONCLUSION}

It is inevitable for the global economy that the destructive effect caused by the pandemics has posed a great threat to profitable or non-profitable organizations and individual investors. Specifically, for all investors, the misty financial situation induced a suspicious atmosphere for investment, making CAPM gradually popular among the financial market. Our research recognized and analyzed the TV and broadcasting market variation during the before and during COVID-19 periods using the Fama-French five-factors model. Based on the analysis, we found out that the TV industries are relatively active with reaction to the pandemics. Specifically speaking, the HML, RMW, and CMA factors became significant that we have evidence that in this industry, companies that with high-value stock and robust were likely to be more attractive to the investors. Moreover, the CMA factor shows negative coefficients in the multiple regression model, demonstrating that aggressive investment is probably profitable in the TV and broadcasting industries in the U.S. In conclusion, the global market is in the recessive period while the TV and broadcasting industries in the U.S. are more effective and profitable, within which larger TV companies have a great tendency to be financially focused on.

\section{REFERENCES}

[1] Markowitz, Harry. "The utility of wealth." Journal of political Economy 60.2 (1952): 151-158.

[2] Chenoweth, M. , et al. "A Pioneer in Tropical Meteorology: William Sharpel" s Barbados Weather Journal, April-August 1680." Bulletin of the American Meteorological Society 88.12(2007):1957-1964.

[3] Lintner, J. . "Security Prices, Risk, and Maximal Gains From Diversification." Journal of Finance 20.4(1965):587-615.

[4] Thomas, S. B., and S. C. Quinn . "The Tuskegee Syphilis Study, 1932 to 1972: implications for HIV education and AIDS risk education programs in the black community. "American journal of public health

[5] Boamah, Nicholas Addai, et al. "Regionally Integrated Asset Pricing on the African Stock Markets: Evidence from the Fama French and Carhart Models." Journal of Economics and Business, vol. 92, 2017, pp. 29-44., doi:10.1016/j.jeconbus.2017.04.002

[6] Lin, Qi. "Noisy Prices and the Fama-French FiveFactor Asset Pricing Model in China." Emerging Markets Review, vol. 31, 2017, pp. 141-163., doi:10.1016/j.ememar.2017.04.002.

[7] Kubota, Keiichi, and Hitoshi Takehara. "Does the Fama and French Five-Factor Model Work Well in Japan?" International Review of Finance, vol. 18, no. 1, 2017, pp. 137-146., doi:10.1111/irfi.12126.

[8] BOSHKOSKA, MERI, and NIKOLCHE JANKULOVSKI. "Coronavirus Impact on Global Economy." Annals of "Constantin Brancusi" University of Targu-Jiu. Economy Series, no. 4, Sept. 2020, pp. 18-24.

[9] SPÂNULESCU, Ion, and Anca GHEORGHIU. "The Impact of Coronavirus Covid-19 on World Economy -- an Econophsics Approach and Model." Hyperion International Journal of Econophysics \& New Economy, vol. 13, no. 1, Jan. 2020, pp. 7-19.

[10]Matos, Paulo, et al. "COVID-19, Stock Market and Sectoral Contagion in US: A Time-Frequency Analysis." Research in International Business and Finance, vol. 57, Oct. 2021. 
[11] Fama, E. F. , \& French, K. R. . (1993). Common risk factors in the returns on stocks and bonds. Journal of Financial Economics, 33(1), 3-56.

[12] ResearchAndMarkets.com The "Television Network Global Market Report 2020-30: COVID19 Implications and Growth" [N] https://www.prnewswire.com/newsreleases/television-network-industry-report-20202030---trends-and-implications-of-the-covid-19pandemic-301079398.html

[13]MarketWatch. (2021, April 16). Netflix Inc. Retrieved from: https://www.marketwatch.com/investing/stock/nflx

[14]MarketWatch. (2021, April 16). Spotify Technology S.A. Retrieved from: https://www.marketwatch.com/investing/stock/spot ?mod=mw_quote_tab

[15]CSIMarket. (2021). Valuation Information \& Trends. Broadcasting Media \& Cable TV Industry. Retrieved from: https://csimarket.com/Industry/industry_valuation_ ttm.php?pe\&ind=902

[16]Netflix investor. (2021, April 25). Stock-information. Retrieved from: https://ir.netflix.net/stockinformation/stock-quote/default.aspx

[17]Netflix investor. (2021, April 25). Financials. Retrieved from: https://ir.netflix.net/financials/annual-reports-andproxies/default.aspx

[18]"MarketLine Industry Profile: Broadcasting \& Cable TV in North America." Broadcasting \& Cable TV Industry Profile: North America, Aug. 2020, pp. 145 . 